\title{
Linking photoacclimation responses and microbiome shifts between depth-segregated sibling species of reef corals
}

Carlos Prada ${ }^{1{ }^{*}}$, Tomás López-Londoño ${ }^{2+}$, F. Joseph Pollock ${ }^{2,3}$, Sofia Roitman², Kim B. Ritchie ${ }^{4}$, Don R. Levitan ${ }^{5}$, Nancy Knowlton ${ }^{6}$, Cheryl Woodley ${ }^{7}$, Roberto Iglesias-Prieto ${ }^{1}$, Mónica Medina ${ }^{1}$

${ }^{1}$ University of Rhode Island, Department of Biological Sciences, Kingston, RI 02881, USA

${ }^{2}$ Pennsylvania State University, Department of Biology, 208 Mueller Lab, University Park, PA 16802, USA

${ }^{3}$ The Nature Conservancy, Hawai'i and Palmyra Programs, 923 Nu'uanu Avenue, Honolulu, HI 96817, USA

${ }^{4}$ University of South Carolina Beaufort, Department of Natural Sciences, 801 Carteret Street, Beaufort, SC 29906, USA

${ }^{5}$ Florida State University, Department of Biological Science, Tallahassee, FL 32306, USA

${ }^{6}$ National Museum of Natural History, Smithsonian Institution, Washington, DC 20560, USA

${ }^{7}$ National Oceanic and Atmospheric Administration, National Ocean Service, National Centers for Coastal Ocean Sciences, Hollings Marine Laboratory, Charleston, SC 29412, USA.

*Corresponding author: prada@uri.edu.

${ }^{+}$Equal contribution.

\section{ABSTRACT}

Metazoans host complex communities of microorganisms that include dinoflagellates, fungi, bacteria, archaea, and viruses. Interactions among members of these complex assemblages allow hosts to adjust their physiology and metabolism to cope with environmental variation and occupy different habitats. Here, using reciprocal transplantation across depths, we studied adaptive divergence in the Caribbean corals Orbicella annularis and $O$. franksi. When transplanted from deep to shallow, $O$. franksi experienced fast photoacclimation, low mortality, and maintained a consistent bacterial community. In contrast, 0 . annularis experienced higher mortality, and limited photoacclimation when transplanted from shallow to deep. The photophysiological collapse of $O$. annularis in the deep environment was associated with an increased microbiome variability and reduction of some bacterial taxa. Differences in the symbiotic algal community were more pronounced between coral species than between depths. Our study suggests that these sibling species are adapted to distinctive light environments partially driven by the algae photoacclimation capacity and the microbiome robustness, highlighting the importance of niche specialization in symbiotic corals for the maintenance of species diversity. Our findings have implications for the management of these threatened Caribbean corals and the effectiveness of coral reef restoration efforts.

Keywords: corals, symbiosis, microbiome, photobiology, ecophysiology, niche divergence 


\section{INTRODUCTION}

Understanding how microbial biodiversity interacts with their host's physiology is essential for understanding animal ecology and evolution (Thompson et al. 2015). Microbial communities often finetune their host's physiology to cope with environmental variation across habitats (Gilbert et al. 2010). Reef-building corals (Cnidaria: Scleractinia) form a symbiotic association with dinoflagellates, which allow corals to thrive on the ocean's euphotic zone along a strong depth-mediated light gradient (Stoddart 1969). Corals living at different depths possess distinctive physiological and morphological traits to optimize energy acquisition which results from genotypic and phenotypic variation within and between coral species (Vermeij and Bak 2002; Hoogenboom et al. 2008). Coral colonies at different depths may host distinctive symbiotic algae with contrasting photoacclimation capabilities that grant their hosts the ability to thrive in certain light environments (Rowan et al. 1997; Warner et al. 2006). Because of these differences in photoacclimation and the prevalence of specific associations with coral hosts, zonation by light has been regarded as a primary form of niche partitioning in symbiotic corals (Iglesias-Prieto et al. 2004).

While the influence of different species of symbiotic algae on the ecophysiology of reef-building corals has been studied, the effect of other coral-associated microorganisms is less known, specially across depth-segregated species (Rohwer et al. 2002; Pantos et al. 2015). However, the interest on coralassociated microbes and their roles in maintaining health and preventing diseases has increased substantially (Kellogg et al. 2013; Peixoto et al. 2017). From an eco-evolutionary perspective, the evidence suggests that coral-associated bacterial assemblages can be highly variable although "footprints" of unique microbial assemblages appear to be mediated by a combination of host species and local environmental conditions (Rohwer et al. 2002; Marchioro et al. 2020). These patterns indicate that bacterial communities, like photosynthetic dinoflagellates, could also be spatially structured and segregated along environmental gradients.

Recently diverged coral species that differ in their vertical distribution are ideal systems to study the microbiota-animal relationship as a potential basis for habitat specialization. The Orbicella species complex, dominant in Caribbean reefs, was initially regarded as one species with ecotypic variation, but recent research revealed three species partially segregated by depth (Weil and Knowlton 1994; Fukami et al. 2004; Levitan et al. 2011). O. annularis is a high-light specialist which forms columns with senescent edges, while $O$. franksi is a low-light specialist forming irregular mounds and plates. $O$. 
faveolata form massive mounds and can overlap with both $O$. annularis and $O$. franksi habitats. The three Orbicella species are closely related with incomplete lineage sorting across nuclear and mitochondrial markers (Weil and Knowlton 1994; Fukami et al. 2004). The symbiotic dinoflagellate communities (Rowan et al. 1997; Kemp et al. 2015) as well as the photobiology of this species complex have been extensively studied (Warner et al. 2006; Scheufen et al. 2017), enabling the identification of important differences mediated by environmental gradients. The Orbicella-associated bacterial communities have also been examined (Kellogg et al. 2013; Roitman et al. 2020). Therefore, this coral species complex offers an ideal system for the study of how species specialize to live in different habitats through adaptive divergence.

Using a reciprocal transplant experiment between shallow and deep environments in Bocas del Toro (Caribbean Panama), we studied adaptive divergence between the youngest sister species within the Orbicella species complex, $O$. annularis and $O$. franksi. We surveyed colonies for survivorship and characterized the algal symbiont and microbial communities across habitats. We also evaluated if these recently diverged species have also diverged physiologically along depth-mediated light gradients. We hypothesize that $O$. franksi and $O$. annularis exploit different light niches, coexisting in Caribbean reefs with minimal competition for space. Our findings suggest that despite being so young $(<500 \mathrm{~K})$ (Pandolfi et al. 2002), these two sister species have diverged and fine-tuned their photoacclimation capabilities and microbial symbionts to maximize efficiency in their own light environments.

\section{MATERIALS AND METHODS}

\section{Reciprocal transplantation}

To study the effects of depth and light in $O$. annularis and $O$. franksi, colonies were reciprocally transplanted between shallow and deep environments at Bocas del Toro, Panama (latitude: 9.327222, longitude: -82.203889). The study site is located on the slope of a relative narrow reef protected on all sides by islands and has been monitored for coral spawning for two decades (Levitan et al. 2011). This location is ideal to study adaptation across depths because the vertical distribution of these species is compressed to shallower depths ( 2-9 m) compared to other sites in the Caribbean (Van Veghel 1994; Pandolfi and Budd 2008), although maintaining the typical vertical zonation pattern (O. annularis in shallow-water and O. franksi in deeper-water). 
In September 2014, fully pigmented coral clonemate fragments ( $\sim \mathrm{cm}$ in diameter) were collected from the edges of $O$. franksi colonies and vertically oriented colonies of $O$. annularis. Same genotypes (clonemates) of both species ( $n \leq 28$ ) were exposed to both shallow and deep environments. Coral fragments were collected from two depths in which each species was abundant: shallow for 0 . annularis (3-4 m) and deep for $O$. franksi (7-8 m). Coral fragments from each species were transplanted to polyvinyl chloride (PVC) panels placed near the original depth of collection (3.5 $\mathrm{m}$ and 9.5) where they were left to heal and acclimate for one week. Subsequently, $O$. annularis colonies were transplanted from shallow to shallow (S-S) $(n=27)$ and shallow to deep (S-D) $(n=30)$. Similarly, $O$. franksi colonies were transplanted from deep to shallow (D-S) $(n=44)$ and deep to deep (D-D) $(n=28)$.

To test for differential mortality across depths, we visually inspected colonies six months after transplantation in March 2015. One detached individual from O. annularis transplanted deep was discarded from this analysis. A one-tailed Fisher exact test was used to assess differences in survivorship among sites. To standardize the fitness (i.e., survival) advantage on the original depth over the opposite depth for each species, differences in fitness were divided over the average fitness on each particular habitat (Hereford 2009).

Samples were collected in accordance with local regulations under CITES permits PWS2014-AU-002155 and 12US784243/9 and Panama permit number SE/A-94-13.

\section{Environmental parameters}

To characterize the effect of the water optical properties on light availability across depths, we measured the diffuse attenuation coefficient for downwelling irradiance $\left(K_{d}\right)$ at the beginning of the experiment. $K_{\mathrm{d}}$ was calculated by measuring changes in light intensities across the depth gradient using the cosine-corrected PAR sensor of a Diving-PAM (Walz), previously calibrated against a manufacturercalibrated quantum sensor (LI-1400, LI-COR). The light intensity at each transplant site, expressed as the percentage of incident light, was calculated (Kirk 2011; López-Londoño et al. 2021). Variation in temperature and relative light levels throughout the duration of the experiment was recorded every 30 min by Onset HOBO data loggers (UA-002-64, Onset Computer Corporation) attached to the PVC panels. 


\section{Photophysiology}

122 To test how depth-dependent light variation affects the photosynthetic condition of corals' symbiotic 123 algae, we measured the chlorophyll $a(\mathrm{Chl} a)$ fluorescence using pulse amplitude modulated (PAM) 124 fluorometry (Diving-PAM). Measurements were recorded on ten fragments from each species at each 125 depth before transplantation, and every two/three days during the week after transplantation. The 126 effective quantum yield $\left(\Delta F / F_{\mathrm{m}}{ }^{\prime}\right)$ of photosystem II (PSII) was recorded at noon during peak sunlight 127 exposure, and the maximum quantum yield of PSII $\left(F_{v} / F_{m}\right)$ at dusk. The maximum excitation pressure 128 over PS II $\left(Q_{m}\right)$ was calculated as $Q_{m}=1-\left[\left(\Delta F / F_{m}{ }^{\prime}\right) /\left(F_{v} / F_{m}\right)\right]$ (Iglesias-Prieto et al. 2004). $\Delta F / F_{m}{ }^{\prime}$ was also 129 recorded in situ on coral colonies of $O$. annularis $(n=38)$ and $O$. franksi $(n=67)$ randomly distributed over the full depth range of each species. In order to calculate $Q_{m}$ on these colonies, we estimated $F_{v} / F_{m}$

131 based on a linear regression with data obtained from a sub-sample of colonies randomly distributed 132 over the same depth range ( $n=10$ and $n=21$ for 0 . annularis and $O$. franksi, respectively). Pearson's 133 correlation coefficients revealed a strong positive correlation between $F_{v} / F_{m}$ and depth in both $O$. 134 annularis and $O$. franksi $\left(R^{2}=0.85, p<0.01\right.$ and $\left.R^{2}=0.83, p<0.01\right)$, indicating a reliable prediction of $135 F_{v} / F_{m}$ across depths. We used linear regression models to explore the relationship between $Q_{m}$ and depth for $O$. annularis and $O$. franksi based on evidence that $Q_{m}$ varies in a pattern that is roughly linear with depth in other coral species (Iglesias-Prieto et al. 2004). An Analysis of Covariance (ANCOVA) was conducted to test for differences in slopes and intercepts among regression models (interaction of species with depth). Due to technical issues with the Diving-PAM (loss in hermeticity), samples from the transplant experiment were transported from the transplant sites to the boat in a dark container to record measurements. During this short period of dark acclimation ( $<5 \mathrm{~min}$ ), some components of the

142 non-photochemical quenching could have relaxed (Ralph and Gademann 2005), leading to a slight, yet

143 nearly constant, underestimation of the $\Delta F / F_{m}{ }^{\prime}$ recorded at noon and, as a result, of $Q_{m}$ in all corals.

144 Analyses were conducted using R version 3.6.1 (R Core Team 2015).

Microbiome

Small Subunit Ribosomal RNA (16S) amplicon library preparation and sequencing, sequence quality

147 control and initial data processing

148 We quantified coral-associated microbiome communities in coral transplants to test if adaptive divergence between $O$. annularis and $O$. franksi is in part due to their microbial communities. Tissue 
150

151

152

153

154

155

156

157

158

159

160

161

162

163

164

165

166

167

168

169

170

171

172

173

174

175

176

177

178

179

180

samples were collected at the end of the transplant experiment using $1 / 8^{\prime \prime}$ metal corers by divers wearing Nitrile gloves and were immediately deposited in whirl pack bags. Once returned to the boat, each sample was gently washed with filter-sterile $(0.2 \mu \mathrm{m})$ seawater, deposited in a sterile cryovial, and immediately preserved in liquid nitrogen. We extracted DNA from coral tissue samples using the MoBio Powersoil DNA Isolation Kit (MoBio Laboratories). Two-stage amplicon PCR was performed on the V4 region of the $16 \mathrm{~S}$ small subunit prokaryotic rRNA gene (Apprill et al. 2015; Roitman et al. 2020). First, 30 PCR cycles were performed using 515F and 806R primers (underlined) with linker sequences at the 5' ends: 515F_link (5'-ACA CTG ACG ACA TGG TTC TAC AGT GCC AGC MGC CGC GGT AA-3') and 806Rb_link (5'-TAC GGT AGC AGA GAC TTG GTC TGG ACT ACH VGG GTW TCT AAT-3'). Each $20 \mu \mathrm{L}$ PCR reaction was prepared with $9 \mu \mathrm{L}$ 5Prime HotMaster Mix (VWR International), $1 \mu \mathrm{L}$ forward primer $(10 \mu \mathrm{M}), 1 \mu \mathrm{L}$ reverse primer $(10 \mu \mathrm{M}), 1 \mu \mathrm{L}$ template DNA ( $20 \mathrm{ng} / \mu \mathrm{L})$, and $8 \mu \mathrm{L}$ PCR-grade water. PCR amplifications consisted of a 3 min denaturation at $94{ }^{\circ} \mathrm{C}$; 30 cycles of $45 \mathrm{~s}$ at $94{ }^{\circ} \mathrm{C}, 60 \mathrm{~s}$ at $50{ }^{\circ} \mathrm{C}$ and $90 \mathrm{~s}$ at $72{ }^{\circ} \mathrm{C}$; and $10 \mathrm{~min}$ at $72{ }^{\circ} \mathrm{C}$. Amplicons were barcoded with Fluidigm barcoded Illumina primers (8 cycles) and pooled in equal concentrations for sequencing. The amplicon pool was purified with AMPure XP beads and sequenced on the Illumina MiSeq sequencing platform at the DNA Services Facility at the University of Illinois at Chicago. Sequences were submitted to the National Center for Biotechnology Information (NCBI) Short Read Archive (SRA) under project number PRJNA717688.

Initial processing of $16 \mathrm{~S}$ libraries was performed using the Quantitative Insights Into Microbial Ecology (QIIME; v1.9) package (Caporaso et al. 2010b). Primer sequences were trimmed, paired-end reads merged, and QIIME's default quality-control parameters were used to split libraries among samples. Chimeras were removed and 97\%-similarity OTUs picked using USEARCH 7.0 (Edgar 2010), QIIME's subsampled open-reference OTU-picking protocol (Rideout et al. 2014), and the 97\% GreenGenes 13_8 reference database (McDonald et al. 2012). Taxonomy was assigned using UCLUST and reads were aligned against the GreenGenes database using PyNAST (Caporaso et al. 2010a). FastTreeMP (Price et al. 2010) was used to create a bacterial phylogeny with constraints defined by the GreenGenes reference phylogeny. OTUs classified as "unknown" (i.e., sequences not classified at the kingdom level), chloroplast, mitochondria, or other potential contaminants were removed. Low coverage samples $(<223$ useable reads) were omitted. Unless otherwise stated, downstream microbiome analyses and figure generation were performed in $\mathrm{R}$ version 3.2.5 (R Core Team 2015) using the phyloseq and ggplot2 packages (Wickham 2009; McMurdie and Holmes 2013). 
To quantify differences among treatments, we used weighted UniFrac (wUniFrac) dissimilarity matrices using OTU-level relative abundances. Significant differences in bacterial assemblages were assessed by permutational multivariate analysis of variance (PERMANOVA) with wUniFrac distances and the explanatory variables host species and depth (i.e., vegan::adonis) (Oksanen et al. 2017). Both overall (i.e., O. annularis and O. franksi) and species-specific models (i.e., O. annularis or O. franksi) were tested. Heatmaps of OTU abundances were created using the phyloseq::plot_heatmap function (McMurdie and Holmes 2013). Within-category microbiome variability (i.e., wUniFrac distance) was calculated in QIIME using the make_distance_boxplots function, which also assesses significant differences in microbiome variability among categories via pairwise, nonparametric t-tests (1000 Monte Carlo permutations) with Bonferroni correction. To test for significant differences in OTU abundances across host species and depths, we employed negative binomial modelling using DESeq2 (McMurdie and Holmes 2013; Love et al. 2014). Both the overall (i.e., O. annularis and O. franksi) and species-specific models (i.e., O. annularis or 0 . franksi) were tested. P-values for the significance of contrasts were generated based on Wald statistics, and false discovery rates were calculated using the Benjamini-Hochberg procedure.

\section{Microalgal communities}

processing

To quantify differences in dinoflagellate communities across species and depths, we used a two-stage

200 amplicon PCR on the same DNA that was extracted and used for the $16 \mathrm{~S}$ amplification. We amplified the 201 Internal Transcribed Spacer 2 (ITS2) rRNA marker gene commonly used for identification of

202 Symbiodiniaceae (Hume et al. 2019). The primers used to quantify differences in the symbiotic algal 203 communities were modified versions of the ITS-DINO forward (5'-ACA CTG ACG ACA TGG TTC TAC AGT 204 GAA TTG CAG AAC TCC GTG-3') and ITS2Rev2 (5'- TAC GGT AGC AGA GAC TTG GTC TCC TCC GCT TAC TTA 205 TAT GCT T-3') (Stat et al. 2009) that include the universal primer sequences required for Illumina MiSeq amplicon sequencing, namely common sequence 1 (CS1) and common sequence 2 (CS2). The PCR amplification was structured as follows: 2 min of denaturation at $94^{\circ} \mathrm{C} ; 35$ cycles of $45 \mathrm{~s}$ at $94{ }^{\circ} \mathrm{C}, 60 \mathrm{~s}$ at

$20855^{\circ} \mathrm{C}$, and $90 \mathrm{~s}$ at $68^{\circ} \mathrm{C}$; then finally $7 \mathrm{~min}$ at $68^{\circ} \mathrm{C}$. Once the PCR reactions were finished, samples were 209 held at $4{ }^{\circ} \mathrm{C}$ before sequencing. Samples were sequenced using the Illumina MiniSeq platform at the 
211 processing and quality checks (Hume et al. 2019). Quality checking was performed using mothur (Schloss

212 et al. 2009), followed by taxonomic identification using blastn. The SymPortal pipeline then subdivides

213 sequences into genus groupings and identified type profiles, referred to as defining intragenomic

214 sequence variants (DIVs). Type profiles were only identified if a variant contained more than 200

215 sequences, and the sequences were subsequently named based on whether they had been used in the

216 definition of the DIVs. The resulting absolute and relative count tables were imported into R version

$217 \quad 3.5 .2$ (R Core Team 2015) for downstream analyses and figure generation using the phyloseq (McMurdie

218 and Holmes 2013), vegan (Oksanen et al. 2017), microbiome (Lahti and Shetty 2017), and ggplot2

219 (Wickham 2009) packages.

ß-diversity group significance testing

221 To compare dinoflagellate communities across samples, we constructed Bray-Curtis and Jaccard 222 dissimilarity matrices using absolute abundances. Significant differences in bacterial communities 223 between sample types were assessed by PERMANOVA with Bray-Curtis and Jaccard distances and 224 explanatory variables including host species, season, and depth using the adonis function from the 225 vegan package (Oksanen et al. 2017). We tested overall models that encompassed both species as well 226 as species-specific models.

227 RESULTS

Temperature and irradiance are higher and more variable in shallow environments

229 The $K_{\mathrm{d}}$ near the transplant sites was $0.40 \mathrm{~m}^{-1}$, indicating that corals from the shallow $(3.5 \mathrm{~m})$ and deep $230(9.5 \mathrm{~m})$ sites receive respectively $\sim 25 \%$ and $\sim 2 \%$ sea surface irradiance. Across the vertical distribution 231 range of each species (Fig 1a), it is estimated that the light intensity varies between $18 \%$ and $62 \%$ sea 232 surface irradiance for 0 . annularis and between $5 \%$ and $33 \%$ for 0 . franksi. Relative light levels recorded 233 by data loggers indicated that the light exposure was nearly 5 times more variable in shallow water than 234 in deep water. Daily temperatures were significantly higher in the shallow site $\left(28.85 \pm 0.96{ }^{\circ} \mathrm{C}\right.$, mean \pm 235 s.d.) than in the deep site $\left(28.46 \pm 0.88^{\circ} \mathrm{C}\right.$; $t$-value $=3.92, p<0.001$; Fig. 1b). However, based on the 236 scaling quotient of temperature $\left(Q_{10}\right)$ of Orbicella spp. (Scheufen et al. 2017), it is estimated that the 237 metabolic rate variation due to differences in temperature among sites is negligible ( $\sim \%)$. 
(a)

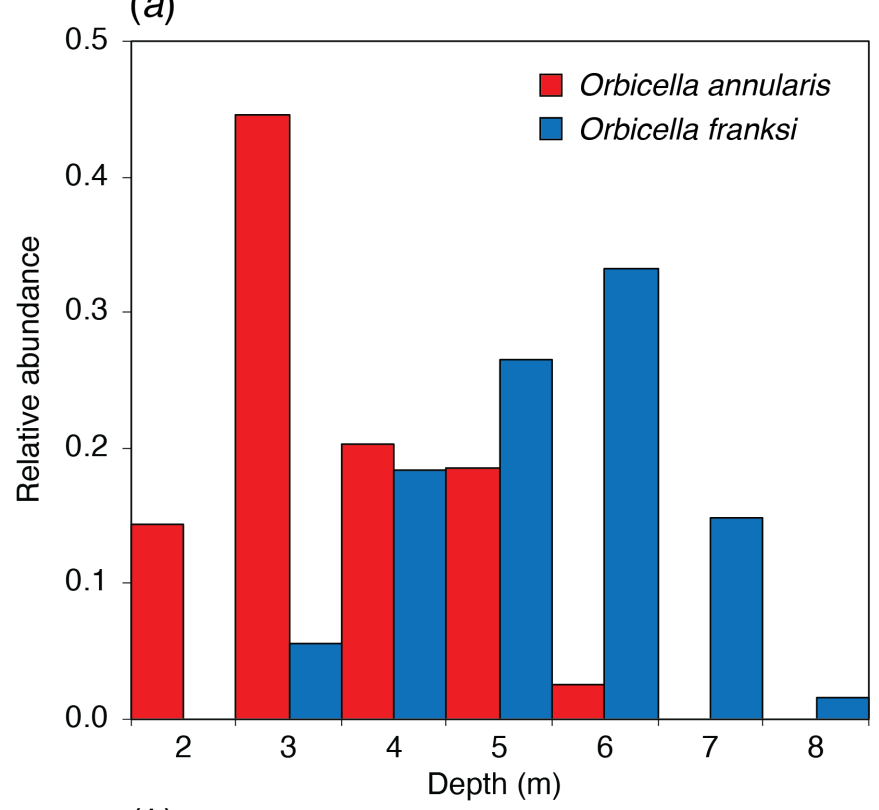

(b)

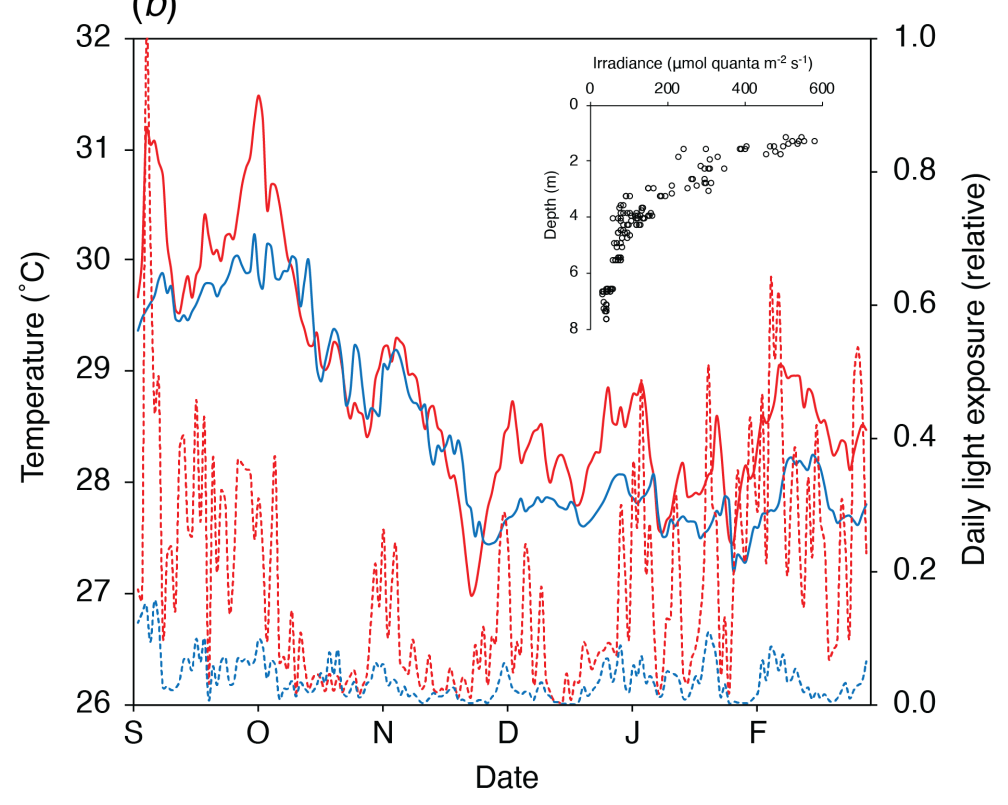

Figure 1. (a) Vertical distribution of $O$. annularis and $O$. franksi around the transplant sites in Bocas del Toro, Panamá, previously established as part of the long-term monitoring of coral spawning (Levitan et al. 2011). (b) Variation of the mean daily temperature (continuous lines) and relative light exposure (discontinuous lines) at the shallow (red) and deep (blue) transplant sites. The inset shows the light intensity variation across depths used to calculate the local $K_{\mathrm{d}}$. 


\section{O. annularis experiences greater mortality in deep environments}

248

249

250

251

252

253

254

Transplantation of $O$. annularis S-D $\left(\Delta_{\text {depth }}=6 \mathrm{~m}\right)$ resulted in $26 \%$ mortality (Fisher exact test: $p=0.003$ ) and was significantly higher than that of $O$. franksi colonies transplanted D-D (4\% mortality, Fisher exact test: $p=0.04)$. $O$. franksi therefore has an advantage of $26 \%$ over $O$. annularis in deep habitats. In contrast, $O$. franksi when transplanted D-S did remarkably well with only $2 \%$ mortality (Fisher exact test: $p=0.63)$. Mortality of the two species was not significantly different ( $0 \%$ mortality, Fisher exact test: $p=$ $0.60)$, suggesting that $O$. franksi in shallow areas has no perceivable short-term (< six months) disadvantage relative to $O$. annularis (Fisher exact test: $p=0.60$ ).

\section{Photoacclimation of 0 . annularis is insufficient to compensate for reduced light}

Symbionts of $O$. annularis exhibited a significant increase in $F_{\mathrm{v}} / F_{\mathrm{m}}$ when transplanted S-D $(0.622 \pm 0.034)$ relative to corals transplanted S-S $(0.541 \pm 0.007)(t$-value $=-6.25, p<0.01)$. On the contrary, symbionts of $O$. franksi transplanted $D-S$ experienced a reduction in $F_{v} / F_{m}(0.470 \pm 0.052)$ relative to $D-D$ transplants $(0.630 \pm 0.020 ; t$-value $=0.55, p<0.01)$. Transplantation of $O$. annularis S-D induced a significant reduction in $Q_{m}(0.008 \pm 0.076)$, relative to $S$-S transplantation $(0.216 \pm 0.163 ; t$-value $=3.67$, $p<0.01$ ) (Fig. 2a); while $O$. franksi exhibited a significant increase in $Q_{m}(0.226 \pm 0.156)$ when transplanted D-S, relative to D-D transplants $(0.073 \pm 0.056 ; t$-value $=3.26, p<0.01)$ (Fig. $2 b$ ).

Estimations of $Q_{m}$ on coral colonies along the vertical distribution of each species ranged from 0.099 to 0.673 in O. annularis and from 0.020 to 0.492 in 0 . franksi (Fig. 2c). We found a significant species by depth interaction $\left(\mathrm{F}_{(1,102)}=28.78, p<0.001\right)$, indicating that the slope of the regression model describing the relationship between $Q_{m}$ and depth was significantly different between species, being more than twice as pronounced in 0 . annularis $\left(\mathrm{m}=-0.13 ; R^{2}=0.71, p<0.001\right)$ than in 0 . franksi $\left(\mathrm{m}=-0.05 ; R^{2}=0.50\right.$, $p<0.001)$. The linear regression of $Q_{m}$ with depth indicated that the potential depth limit described by the bioenergetics of the coral-algae symbiosis (i.e., where $Q_{m}$ reaches the minimum theoretical value of 0 ) is 5.5. $\mathrm{m}$ for $\mathrm{O}$. annularis and $7.8 \mathrm{~m}$ for $O$. franksi (Fig. 2c), which nearly coincide with the observed lower limit of distribution of both species in the study area (Fig. 1a). 


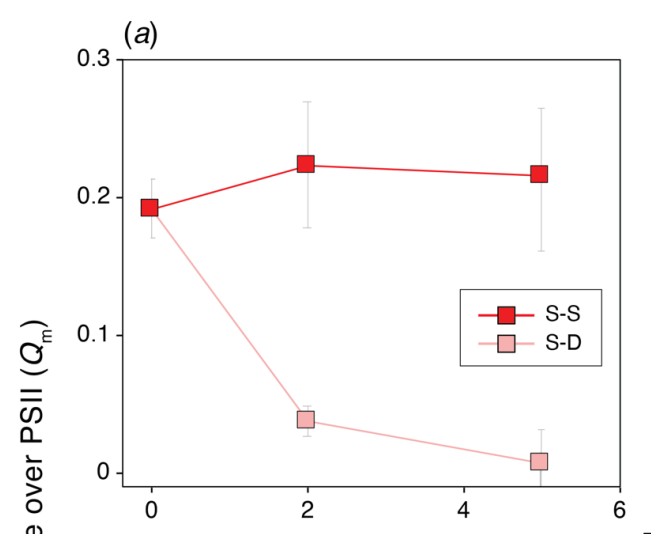

(b)
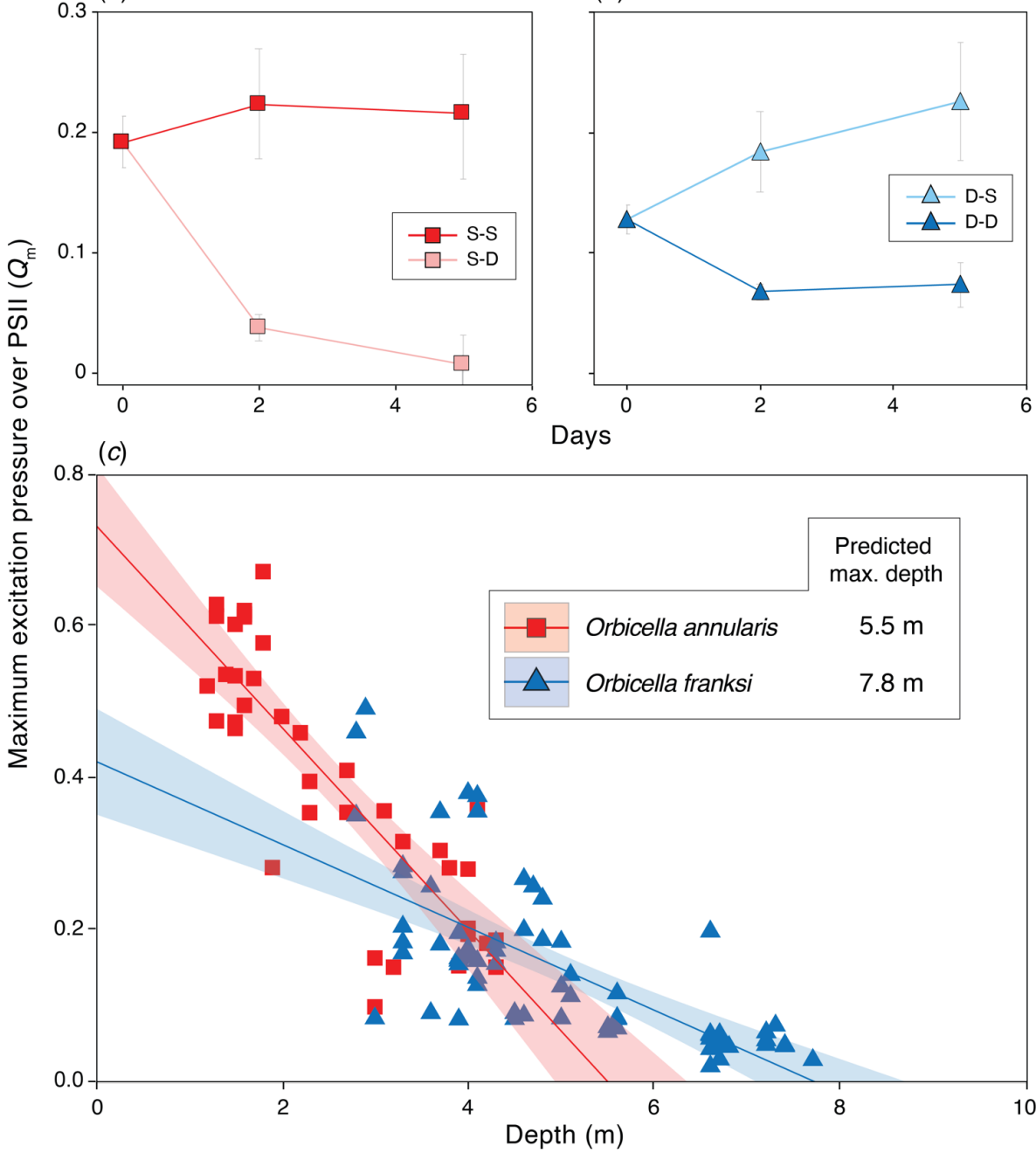

Figure 2. Photoacclimation responses of Orbicella spp. across depths. Maximum excitation pressure over PS II $\left(Q_{m}\right)$ is shown pre- and post-transplantation for $O$. annularis $(a)$ and $O$. franksi $(b)$. Values obtained in $O$. annularis transplanted S-S are shown in dark red while those transplanted S-D in pink. Values from $O$. franksi transplanted D-D are shown in dark blue while those transplanted D-S in light blue. (c) $Q_{m}$ variation in $O$. annularis (red) and $O$. franksi (blue) along a depth gradient. A linear model was used to fit the data and predict the maximum potential depth limit described by $Q_{m}$ for 0 . annularis $\left[Q_{m}=0.735-\right.$ $0.133 *$ depth; $\left.R^{2}=0.71, p<0.001\right]$ and $O$. franksi $\left[Q_{\mathrm{m}}=0.422-0.054 *\right.$ depth; $\left.R^{2}=0.50, p<0.001\right]$. Clear lines represent $95 \%$ confidence intervals.

\section{Changes in depth produces a major shift in 0 . annularis microbiome}

After quality control, sequencing resulted in a total of 577,930 microbial reads (per sample median: 5,758; per sample mean: 9,173) partitioned across 14,274 unique OTUs. Overall, coral-associated prokaryote communities were significantly structured according to depth $(p=0.001)$, but not host 
species ( $p=0.12$ ) or depth by species interaction ( $p=0.86$; PERMANOVA on weighted UniFrac; Fig. 3 ).

The change across depths is mainly driven by $O$. annularis $(p=0.01, \mathbf{F i g}$. 3). The strong response of $O$.

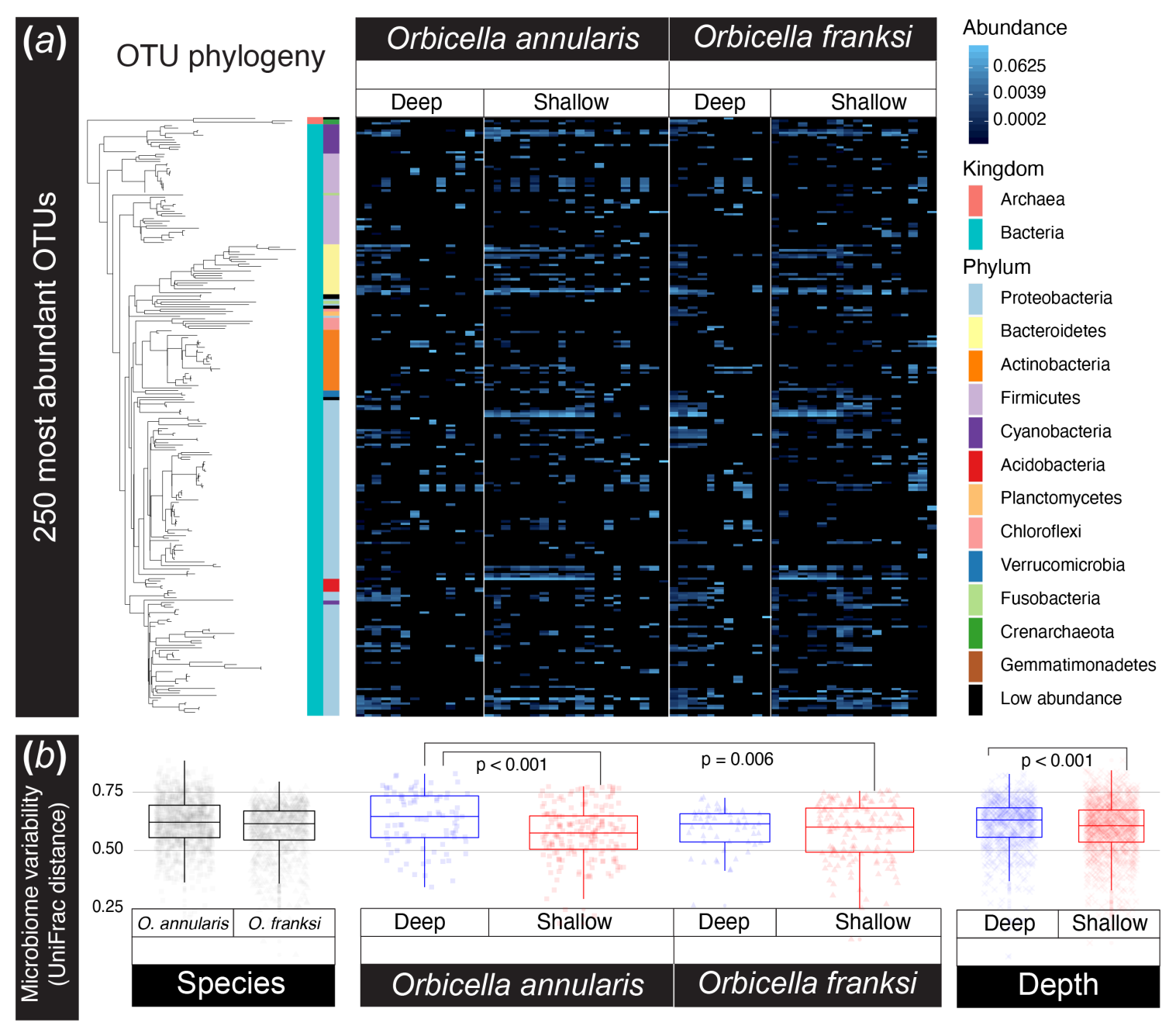

Figure 3. $O$. annularis microbiomes vary across timepoints and depths while $O$. franksi communities remain consistent. (a) Relative abundances of the 250 most common OTUs reveal distinct patterns among $\boldsymbol{O}$. annularis microbiomes at the two transplant depths while $O$. franksi abundance patterns remain largely consistent across treatments. Each column in the heatmap represents an individual microbiome sample and phylogenetic relationships among OTUs are shown on the left (FastTree maximum-likelihood tree). (b) Microbiome variability (i.e., weighted UniFrac distances) was greatest in $O$. annularis corals transplanted to deep waters. Microbiome variability was higher in corals in deep waters than in shallow. 
Ten bacterial taxa were significantly enriched in shallow-water samples. OTUs enriched in shallow-water coral microbiomes are from the bacterial Orders Acidimicrobiales (1 OTU), Alteromonadales (1), Kiloniellales (2), Lactobacillales (1), Neisseriales (1), Oceanospirillales (3), and Synechococcales (1). The mean $\log _{2}$ fold change for enriched OTUs was 5.6.

Microbiome variability did not differ significantly between species with 0 . annularis $(0.592 \pm 0.008$; mean UniFrac distance \pm standard error) and $O$. franksi fragments $(0.582 \pm 0.008)\left(p_{\text {adj }}=0.358\right)$. In contrast, microbiome variability differed significantly between depths, being greatest in $O$. annularis transplanted S-D (0.631 \pm 0.013 ; mean UniFrac distance \pm standard error $)$ and significantly higher than O. annularis transplanted S-S $\left(0.574 \pm 0.008 ; p_{\text {adj }}<0.001\right)$ or $O$. franksi transplanted D-S $(0.580 \pm 0.010$; $\left.p_{\text {adj }}=0.006\right)($ Fig. $3 b)$. The larger microbiome variability in $O$. annularis transplanted deep is consistent with higher mortality and limited photoacclimation potential.

\section{Symbiodiniaceae communities vary across species}

Algal communities of $O$. annularis were significantly different from those of $O$. franksi regardless of the depth to which they were transplanted to ( $p<0.05$; pairwise PERMANOVA on a Bray-Curtis matrix). Symbiodiniaceae genotypes belonging to the genus Symbiodinium (ITS2 type A3) and Cladocopium (C3an, C3an/C3, C7, and C7f) occurred in both coral species, although Cladocopium genotypes were more abundant in O. franksi. Genotypes from the genus Breviolum (B1 and B1/B1t) were detected in high abundances in 0 . annularis, and in many colonies from the shallow site ( $40 \%$ of them) were the only dominant symbiont. Only one $O$. franksi colony transplanted D-S hosted a Breviolum (B1) population. Genotypes belonging to the genus Durusdinium (D1, D1bl, D4, and D4c) were detected only in O. franksi transplanted D-D (Fig. 4). Neither O. annularis nor O. franksi Symbiodiniaceae communities were significantly different when transplanted to a different depth $(p>0.1$; pairwise PERMANOVA on a Bray-Curtis matrix). 


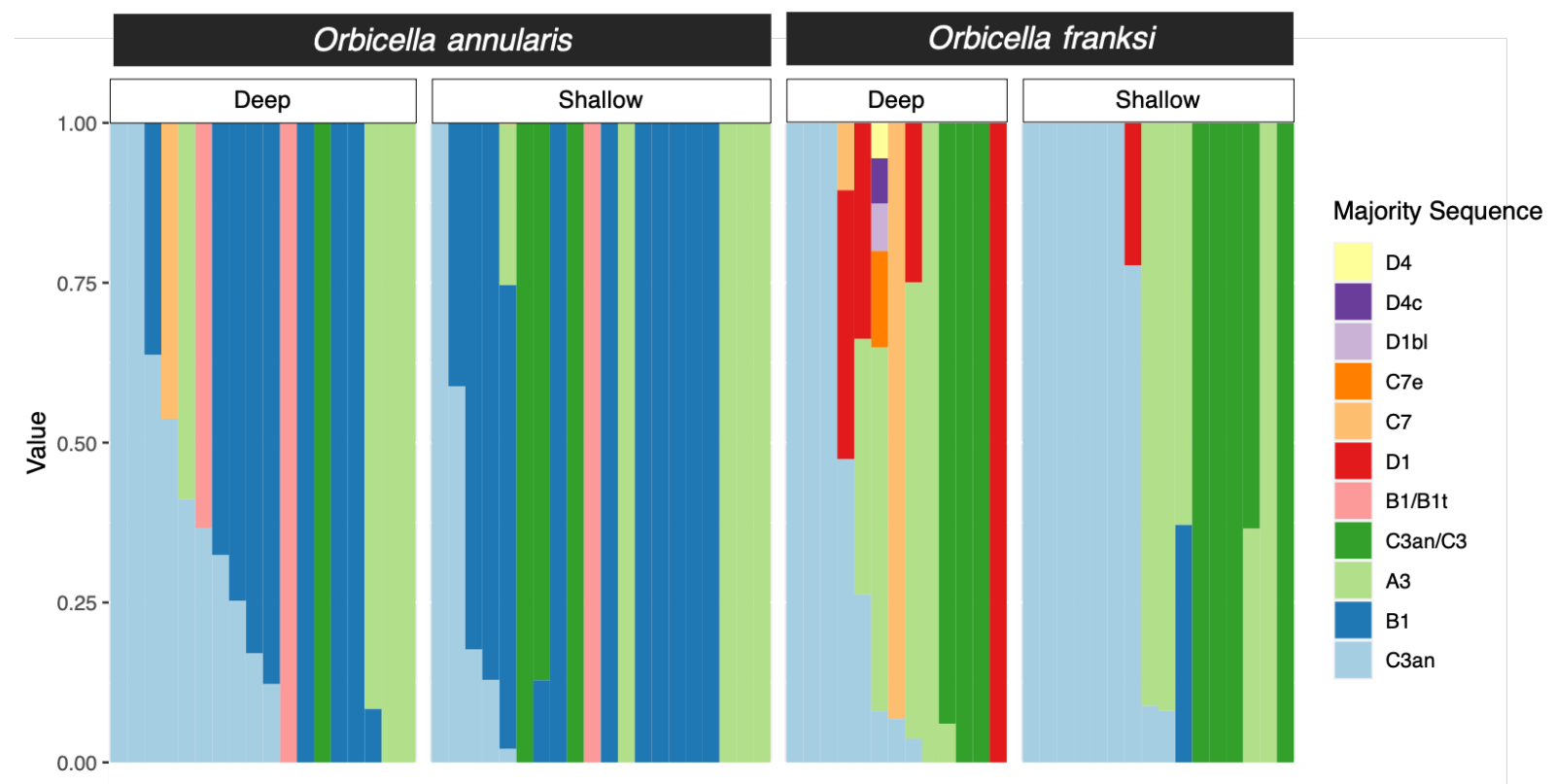

Figure 4. Relative abundance bar plot of Symbiodiniaceae ITS2 profiles identified in Orbicella spp. by Symportal (Hume et al. 2019). Variation in Symbiodiniaceae types is shown by species as well as by depth.

\section{DISCUSSION}

Our study demonstrates that despite being genetically close (Levitan et al. 2011), O. annularis and $O$. franksi have diverged physiologically and occupy distinct light environments in part due to the variation in their associated microbiotas (Symbiodiniaceae and bacterial communities). Following transplantation to deep habitats, $O$. annularis experiences a limited photoacclimation potential and disruption of the photosynthetic performance of its algal symbionts, consistent with increased mortality and significant microbiome community shifts with increased variability. By contrast, $O$. franksi maintained a robust physiological performance, a resilient microbiome composition with no significant community shifts or increased variability, and low mortality at both depths. Our study suggests that $O$. annularis is adapted to shallow environments characterized by a higher and more variable temperature and light regimes, while $O$. franksi is physiologically able to live in both shallow and deep habitats. The niches of these sibling species have diverged, and a large component of the niche separation seems to be related to variations in the photoacclimation capabilities and the microbial community of each species. The absence of $O$. franksi in shallow areas may be related to other ecological aspects such as slow growth in 
an area of intense space competition, a restricted morphological plasticity for regulating the light capture (see below) and/or non-random settlement of recruits across depths (i.e., larval habitat choice).

\section{The vertical distribution couples with the photoacclimation capabilities of each species}

The vertical distribution of $O$. annularis and $O$. franksi is compressed toward shallower depths in Bocas del Toro compared to other clear-water sites in the Caribbean (e.g., Curaçao (Van Veghel 1994) and Belize (Pandolfi and Budd 2008)). The vertical habitat compression in both species is consistent with the $K_{\mathrm{d}}$ measured in Bocas del Toro $\left(0.40 \mathrm{~m}^{-1}\right)$, which is notably higher than in clear-water sites $\left(0.06 \mathrm{~m}^{-1}\right.$ in Curaçao and $0.08 \mathrm{~m}^{-1}$ in Belize (Banaszak et al. 1998; Vermeij and Bak 2002)) and reflects the effect of the heavy rainfall patterns and runoff in the region on the optical properties of the water column (Kaufmann and Thompson 2005). This vertical habitat compression is consistent with other coral reefs exposed to water turbidity (Morgan et al. 2020; López-Londoño et al. 2021) and suggest that the light penetration into the water column associated with the local $K_{\mathrm{d}}$ is a determinant factor for the vertical zonation of Orbicella spp. Despite local differences in the vertical distribution ranges, $O$. annularis consistently occupies well-lit shallow areas of reefs where the potential for increased photosynthesis and calcification rates drives a steep competition for space with other corals. In contrast, 0 . franksi consistently dominates deeper reef areas characterized by low-light conditions and reduced coralgrowth rates (Cohen and Dubinsky 2015).

Our findings indicate that $O$. annularis experiences an almost complete loss of photosynthetic activity when transplanted deep. $O$. annularis fragments photoacclimate to low-light conditions by increasing the light energy conversion efficiency (i.e, increase in $F_{v} / F_{m}$ ) (Hoegh-Guldberg and Jones 1999; Gorbunov et al. 2001). However, the extremely low values of $Q_{m}$ reflect a trivial photosynthetic contribution of $O$. annularis symbionts to the host metabolism due to light-limited photosynthesis (Iglesias-Prieto et al. 2004), suggesting that the photoacclimation potential is insufficient to compensate for the low-light conditions of deep environments. Photoacclimation of $O$. franksi fragments transplanted to the shallow environment resulted in an increased fraction of photo-inactivated PSII reaction centers and capacity for thermal dissipation of excessive light energy absorbed (Hoegh-Guldberg and Jones 1999; Gorbunov et al. 2001). But in contrast to $O$. annularis, the estimated $Q_{m}$ in $O$. franksi do not indicate the occurrence of chronic photoinhibition in the shallow environment nor light-limitation in the deep environment, suggesting that $O$. franksi can maintain a more robust physiological performance across depths. The photoacclimation responses of both species in the transplant experiment were consistent with the rates 
372 of change in $Q_{m}$ across their vertical distribution range, which collectively suggest that the symbiotic

373 algae of $O$. annularis are more sensitive to changes in light intensity with depth than symbionts of $O$.

374 franksi.

375 Colony morphology can help modulate the light capture and photosynthetic energy acquisition along

376 the vertical distribution range of corals (Hoogenboom et al. 2008; Kaniewska et al. 2011). The

377 dominance of $O$. annularis in shallow habitats correlates with its faster vertical growth among Orbicella

378 species (Weil and Knowlton 1994). Its morphology (typically columnar) helps regulate the distribution of

379 light energy for symbiotic algae across the colony surface, representing an advantageous strategy in

380 high-light environments because it reduces the coral tissue area subjected to excessive irradiance

381 (Kaniewska et al. 2011). When transplanted deep, this morphology may lead to acute light energy

382 limitation which, in combination with the insufficient acclimation potential to compensate for low-light,

383 can lead to negative energetic balances for the whole colony and eventual death. $O$. franksi, on the

384 other hand, produce plate-like colonies to maximize light capture in deep environments. When

385 transplanted to shallow well-lit environments, despite a potential for successful photoacclimation as

386 indicated by our results, the plate-like morphology limits the capacity to regulate the internal light

387 climate and allows very slow vertical growth. This slow growth makes $O$. franksi a poor competitor, likely

388 explaining why this species is rare in shallow areas. Alternatively, and not mutually exclusive, their larvae

389 may preferentially settle in low light environments. In fact, adaptation and strong selection across

390 depths, may promote the evolution of habitat choice.

\section{$391 \quad$ Host species drive symbiont communities}

392 Species-specific associations with algal symbionts with contrasting photoacclimation capabilities may be

393 a key axis of differentiation between $O$. annularis and $O$. franksi. Despite the higher and more variable

394 temperature and light intensity in shallow areas, which are known conditions that promote the

395 association with Durusdinium trenchii in other corals (LaJeunesse et al. 2009), this dinoflagellate was not

396 detected in O. annularis colonies. Surprisingly, this thermotolerant symbiont (ITS type D1/D1bl) was

397 found in nearly $20 \%$ of $O$. franksi colonies from the deep environment. The increased abundance of $D$.

398 trenchii in $O$. franksi may be related with the runoff impacts in the water column (e.g., sedimentation

399 and nutrient enrichment), a reduction in light penetration, and the mechanisms by which the coral-algae

400 symbiosis interact with these environmental conditions (Garren et al. 2006). The prevalence of

401 Breviolum genotypes in O. annularis and Cladocopium genotypes in O. franksi, both in the shallow and 
402

403

404

405

406

407

408

409

410

411

412

413

414

415

416

417

418

419

420

421

422

423

424

425

426

427

428

429

430

431

deep transplant sites, is consistent with previous reports (LaJeunesse 2002; Garren et al. 2006) and may indicate the formation of stable associations explained by the photoacclimative capabilities of dinoflagellates and the variability of physical factors within the vertical distribution range of each coral species (LaJeunesse 2002; Iglesias-Prieto et al. 2004). The ITS2 analysis has a low resolution to differentiate linages within the same genus in symbiotic algal communities (LaJeunesse and Thornhill 2011; Stat et al. 2011). It is possible that complementary analysis with other molecular markers improves the phylogenetic resolution of Symbiodiniaceae (i.e., species or population level), detecting differences in cryptic species/populations of Cladocopium spp. or Breviolum spp. uniquely associated with each Orbicella species like in other depth-segregated anthozoans (Prada et al. 2014; Pochon et al. 2015).

\section{Microbiome communities vary across depths and are enriched in shallow habitats}

Several Endozoicomonas OTUs were significantly enriched in shallow habitats. Endozoicimonaceae are diverse gammaproteobacterial symbionts of numerous marine hosts at varying depths and with a wide global distribution (Neave et al. 2016). Members of this group are found in abundance in the tissues of coral species and are considered to be true symbionts of corals which may provide a beneficial function (Bayer et al. 2013; Pantos et al. 2015). Although their function within the coral host is not entirely clear; proposed benefits include nutrient acquisition, microbiome structuring and roles in coral health.

Members of the family Alteromonadaceae and the order Acidimicrobiales were also enriched in shallow areas. Alteromonadaceae belong to a diverse group of heterotrophic gammaproteobacteria known to associate with marine hosts and nutrient rich environments. Members of this group tolerate relatively high temperatures and have been used in coral probiotic studies as coral-associated bacteria capable of scavenging free radicals (Dungan et al. 2020), and therefore could provide similar benefits in shallow, high-light environments. Similarly, Acidimicrobiales are known to be planktonic free-living photoheterotrophs found in both temporal and tropical photic zones (Angly et al. 2016) and are associated with DOM in marine environments (Osterholz et al. 2018).

Finally, corals in shallow areas were also enriched for Alloiococcus and Synechococcus. Alloiococcus belongs to the group of gram-positive lactic acid bacteria, which are recognized for producing bacterial growth inhibitors that function to deter invading bacteria in their hosts (Ring $\varnothing$ et al. 2018).

Synechococcus is a photoautotrophic cyanobacterium found in surface waters harbouring abundant light. Both corals and their symbiotic algae are known to actively feed on Synechococcus (Jeong et al. 
2012; McNally et al. 2017) which is often found as a member of the coral surface mucus microbiome (Marchioro et al. 2020). As a food for corals, it has been suggested that nitrogen-rich Synechococcus cells may increase bleaching recovery and coral health (Meunier et al. 2019).

There is a continuing debate as to the relative role of coral host vs. environment in shaping coral microbiomes. This study demonstrates that the responsiveness of coral microbiomes to environmental conditions differs significantly even among very closely related coral species. These differences in microbiome shifts may be related to the resilience of the coral host and its associated algal community to a particular habitat. Pantos et al. (Pantos et al. 2015) found that environment is the major driver of microbiome structure in Seriatopora hysterix, not host genotype or Symbiodiniaceae strain. Our results do not contradict this finding but suggest that responsiveness to environmental conditions can differ significantly even among very closely related coral taxa.

\section{Implications for coral reef conservation}

A key finding in our study with implications for coral restoration is the increased mortality of $O$. annularis when transplanted to low-light environments. We suggest that to enhance survivorship during restoration, the particular light environment of source populations should be similar to the transplant sites. In this study, due to the high vertical attenuation of light $\left(K_{d}=0.40 \mathrm{~m}^{-1}\right)$, a $6 \mathrm{~m}$ increase in depth resulted in an order of magnitude reduction in irradiance and increased mortality of $O$. annularis by $26 \%$. In a clear-water site (e.g., $\left.K_{\mathrm{d}}=0.06 \mathrm{~m}^{-1}\right)$, this response would be expected to occur with an increase in depth of $\sim 40 \mathrm{~m}$. Giving the expensive nature of coral restoration, equating the light environment of donor and transplant sites will likely increase yield and decrease costs. Minimally, our approach can be used to estimate the maximum theoretical depth for each species in a given location with certain water optical quality, thereby providing guidance when choosing the location and depth for coral transplantation.

The second aspect of our findings is related to microbiome composition in different habitats across reefs. Shallow water reefs are areas of high stress with strong variations in light, temperature and salinity, strong changes in water motion and sediment transport, and more ecological variability. Our study suggests that the microbiome of shallow water specialists like $O$. annularis is fine-tuned to this environment and a reduction in the light field can cascade into drastic changes to host-associated microbial community composition. Increases in temperature as a result of climate change has affected primarily shallow water corals (Bridge et al. 2013; Hughes et al. 2018), suggesting that instability in the 
462

463

464

465

466

467

468

469

470

471

472

473

474

475

476

477

478

479

480

481

482

483

484

485

486

487

488

coral microbiomes of shallow-water corals will increase, likely accelerating coral decline of these reef areas.

Lastly, subtle differences in the water optical conditions can result in changes in the underwater light environment and the vertical distribution of coral species. Most coral reefs around the globe are currently threatened by the direct effects of sediments, pollutants and nutrients associated with coastal development and terrestrial runoff (Carlson et al. 2019). These conditions affect the water optical quality and, as a consequence, the light climate of corals and the survivorship of species at different depths. Although previous studies have suggested that deep-water species are more sensitive to changes in water optical conditions (Vermeij and Bak 2002), our results suggest that at least some shallow-water specialists, like $O$. annularis, can be extremely vulnerable to these changes as their physiology/morphology is specialized for high light habitats. As the degradation of water optical properties in coral reefs continue, shallow-water specialists, which are typically major reef-building species, will likely become rare, shifting the structural and functional integrity of reefs.

\section{CONCLUSION}

Our study suggests that the sibling coral species, $O$. annularis and $O$. franksi, are adapted to distinctive light environments along depth gradients. The limited photoacclimation potential and less robust microbiome community restricts $O$. annularis to shallow, high-light environments. $O$. franksi is more versatile, but other ecological aspects such as slow growth in areas of intense space competition restricts the species to deep environments. These contrasting responses associated with the microbial communities highlight the importance of niche specialization in symbiotic corals for the maintenance of species diversity. Our study has implications on coral reef restoration efforts, providing guidance when choosing the location, depth and light environment for coral transplantation.

\section{ACKNOWLEDGMENTS}

Arcadio Castillo Díaz, Gabriel Jácome and Plinio Góndola from the Smithsonian Tropical Research Institute assisted with field operations at the Bocas del Toro field station. Gaby Swain helped on sample processing. Dr. Benjamin Hume provided assistance on Symbiodiniaceae analysis through the SymPortal framework. 


\section{FUNDING STATEMENT}

This work was supported by NSF grants OCE 1442206 and OCE 1642311; Pennsylvania State University startup funds to MM and RI-P; and NOAA grant NA19NOS4820132. CP was funded by grants from NSF (OIA) 2032919 and USDA National Institute of Food and Agriculture (Hatch) 1017848.

\section{COMPETING INTERESTS}

The authors declare that they have no competing interests.

\section{REFERENCES}

Angly FE, Heath C, Morgan TC, Tonin H, Rich V, Schaffelke B, Bourne DG, Tyson GW (2016) Marine microbial communities of the Great Barrier Reef lagoon are influenced by riverine floodwaters and seasonal weather events. Peerj 4:e1511

Apprill A, McNally S, Parsons R, Webe L (2015) Minor revision to V4 region SSU rRNA 806R gene primer greatly increases detection of SAR11 bacterioplankton. Aquat Microb Ecol 75:129-137

Banaszak A, Lesser M, Kuffner I, Ondrusek M (1998) Relationship between ultraviolet (UV) radiation and mycosporine-like amino acids (MAAS) in marine organisms. Bull Mar Sci 63:617-628

Bayer T, Neave MJ, Alsheikh-Hussain A, Aranda M, Yum LK, Mincer T, Hughen K, Apprill A, Voolstra CR (2013) The microbiome of the Red Sea coral Stylophora pistillata is dominated by tissue-associated Endozoicomonas bacteria. Appl Environ Microbiol 79:4759-4762

Bridge TC, Hoey AS, Campbell SJ, Muttaqin E, Rudi E, Fadli N, Baird AH (2013) Depth-dependent mortality of reef corals following a severe bleaching event: implications for thermal refuges and population recovery. F1000Research 2

Caporaso JG, Bittinger K, Bushman FD, DeSantis TZ, Andersen GL, Knight R (2010a) PyNAST: a flexible tool for aligning sequences to a template alignment. Bioinformatics 26:266-267

Caporaso JG, Kuczynski J, Stombaugh J, Bittinger K, Bushman FD, Costello EK, Fierer N, Pena AG, Goodrich JK, Gordon JI (2010b) QIIME allows analysis of high-throughput community sequencing data. Nat Methods 7:335-336

Carlson RR, Foo SA, Asner GP (2019) Land use impacts on coral reef health: a ridge-to-reef perspective. Front Mar Sci 6:562

Cohen I, Dubinsky Z (2015) Long term photoacclimation responses of the coral Stylophora pistillata to reciprocal deep to shallow transplantation: Photosynthesis and calcification. Front Mar Sci 2

Dungan AM, Bulach D, Lin H, van Oppen MJH, Blackall LL (2020) Development of a free radical scavenging probiotic to mitigate coral bleaching. bioRxiv:2020.2007.2002.185645

Edgar RC (2010) Search and clustering orders of magnitude faster than BLAST. Bioinformatics 26:2460-2461

Fukami H, Budd AF, Levitan DR, Jara J, Kersanach R, Knowlton N (2004) Geographical differences in species boundaries among members of the Montastraea annularis complex based on molecular and morphological markers. Evolution 58:324-337

Garren M, Walsh SM, Caccone A, Knowlton N (2006) Patterns of association between Symbiodinium and members of the Montastraea annularis species complex on spatial scales ranging from within colonies to between geographic regions. Coral Reefs 25:503-512

Gilbert SF, McDonald E, Boyle N, Buttino N, Gyi L, Mai M, Prakash N, Robinson J (2010) Symbiosis as a source of selectable epigenetic variation: taking the heat for the big guy. Phil Trans R Soc B 365:671-678

Gorbunov MY, Kolber ZS, Lesser MP, Falkowski PG (2001) Photosynthesis and photoprotection in symbiotic corals. Limnol Oceanogr 46:75-85

Hereford J (2009) A quantitative survey of local adaptation and fitness trade-offs. Am Nat 173:579-588 
Hoegh-Guldberg O, Jones RJ (1999) Photoinhibition and photoprotection in symbiotic dinoflagellates from reefbuilding corals. Mar Ecol Prog Ser 183:73-86

Hoogenboom MO, Connolly SR, Anthony KRN (2008) Interactions between morphological and physiological plasticity optimize energy acquisition in corals. Ecology 89:1144-1154

Hughes TP, Kerry JT, Baird AH, Connolly SR, Dietzel A, Eakin CM, Heron SF, Hoey AS, Hoogenboom MO, Liu G, McWilliam MJ, Pears RJ, Pratchett MS, Skirving WJ, Stella JS, Torda G (2018) Global warming transforms coral reef assemblages. Nature 556:492-496

Hume BCC, Smith EG, Ziegler M, Warrington HJM, Burt JA, LaJeunesse TC, Wiedenmann J, Voolstra CR (2019) SymPortal: a novel analytical framework and platform for coral algal symbiont next-generation sequencing ITS2 profiling. Mol Ecol Resour 19:1063-1080

Iglesias-Prieto R, Beltran VH, LaJeunesse TC, Reyes-Bonilla H, Thome PE (2004) Different algal symbionts explain the vertical distribution of dominant reef corals in the eastern Pacific. Proc R Soc Lond B 271:1757-1763

Jeong HJ, Du Yoo Y, Kang NS, Lim AS, Seong KA, Lee SY, Lee MJ, Lee KH, Kim HS, Shin W (2012) Heterotrophic feeding as a newly identified survival strategy of the dinoflagellate Symbiodinium. Proc Natl Acad Sci USA 109:12604-12609

Kaniewska P, Magnusson SH, Anthony KRN, Reef R, Kühl M, Hoegh-Guldberg O (2011) Importance of macro- versus microstructure in modulating light levels inside coral colonies. J Phycol 47:846-860

Kaufmann KW, Thompson RC (2005) Water temperature variation and the meteorological and hydrographic environment of Bocas del Toro, Panama. Caribb J Sci 41:392-413

Kellogg CA, Piceno YM, Tom LM, DeSantis TZ, Gray MA, Zawada DG, Andersen GL (2013) Comparing bacterial community composition between healthy and white plague-like disease states in Orbicella annularis using PhyloChip ${ }^{\text {TM }}$ G3 microarrays. PLos ONE 8:e79801

Kemp DW, Thornhill DJ, Rotjan RD, Iglesias-Prieto R, Fitt WK, Schmidt GW (2015) Spatially distinct and regionally endemic Symbiodinium assemblages in the threatened Caribbean reef-building coral Orbicella faveolata. Coral Reefs 34:535-547

Kirk JTO (2011) Light and photosynthesis in aquatic ecosystems. Cambridge University Press, New York

Lahti L, Shetty S (2017) microbiome R package. Tools for microbiome analysis in R.

LaJeunesse T (2002) Diversity and community structure of symbiotic dinoflagellates from Caribbean coral reefs. Mar Biol 141:387-400

LaJeunesse TC, Thornhill DJ (2011) Improved resolution of reef-coral endosymbiont (Symbiodinium) species diversity, ecology, and evolution through psbA non-coding region genotyping. PLos ONE 6:e29013

LaJeunesse TC, Smith RT, Finney J, Oxenford H (2009) Outbreak and persistence of opportunistic symbiotic dinoflagellates during the 2005 Caribbean mass coral bleaching event. Proc R Soc B 276:4139-4148

Levitan D, Fogarty N, Jara J, Lotterhos K, Knowlton N (2011) Genetic, spatial, and temporal components to precise spawning synchrony in reef building corals of the Montastraea annularis species complex. Evolution 65:1254-1270

López-Londoño T, Galindo-Martínez CT, Gómez-Campo K, González-Guerrero LA, Roitman S, Pollock FJ, Pizarro V, López-Victoria M, Medina M, Iglesias-Prieto R (2021) Physiological and ecological consequences of the water optical properties degradation on reef corals. Coral Reefs 40:1243-1256

Love MI, Huber W, Anders S (2014) Moderated estimation of fold change and dispersion for RNA-seq data with DESeq2. Genome Biol 15:550

Marchioro GM, Glasl B, Engelen AH, Serrão EA, Bourne DG, Webster NS, Frade PR (2020) Microbiome dynamics in the tissue and mucus of acroporid corals differ in relation to host and environmental parameters. Peerj 8:e9644

McDonald D, Price MN, Goodrich J, Nawrocki EP, DeSantis TZ, Probst A, Andersen GL, Knight R, Hugenholtz P (2012) An improved Greengenes taxonomy with explicit ranks for ecological and evolutionary analyses of bacteria and archaea. ISME J 6:610-618

McMurdie PJ, Holmes S (2013) phyloseq: an R package for reproducible interactive analysis and graphics of microbiome census data. PLos ONE 8:e61217

McNally SP, Parsons RJ, Santoro AE, Apprill A (2017) Multifaceted impacts of the stony coral Porites astreoides on picoplankton abundance and community composition. Limnol Oceanogr 62:217-234

Meunier V, Bonnet S, Pernice M, Benavides M, Lorrain A, Grosso O, Lambert C, Houlbrèque F (2019) Bleaching forces coral's heterotrophy on diazotrophs and Synechococcus. ISME J 13:2882-2886 
Morgan KM, Moynihan MA, Sanwlani N, Switzer AD (2020) Light Limitation and Depth-Variable Sedimentation Drives Vertical Reef Compression on Turbid Coral Reefs. Frontiers in Marine Science 7:931

Neave MJ, Apprill A, Ferrier-Pagès C, Voolstra CR (2016) Diversity and function of prevalent symbiotic marine bacteria in the genus Endozoicomonas. Appl Microbiol Biotechnol 100:8315-8324

Oksanen J, Blanchet FG, Friendly M, Kindt R, Legendre P, McGlinn D, Minchin PR, O'Hara RB, Simpson GL, Solymos $P$, Stevens MHH, Szoecs E, Wagner H (2017) vegan: Community Ecology Package

Osterholz H, Kirchman DL, Niggemann J, Dittmar T (2018) Diversity of bacterial communities and dissolved organic matter in a temperate estuary. FEMS Microbiol Ecol 94:fiy119

Pandolfi JM, Budd AF (2008) Morphology and ecological zonation of Caribbean reef corals: the Montastraea 'annularis' species complex. Mar Ecol Prog Ser 369:89-102

Pandolfi JM, Lovelock CE, Budd AF (2002) Character release following extinction in a Caribbean reef coral species complex. Evolution 56:479-501

Pantos O, Bongaerts P, Dennis PG, Tyson GW, Hoegh-Guldberg O (2015) Habitat-specific environmental conditions primarily control the microbiomes of the coral Seriatopora hystrix. ISME J 9:1916-1927

Peixoto RS, Rosado PM, Leite DCdA, Rosado AS, Bourne DG (2017) Beneficial microorganisms for corals (BMC): proposed mechanisms for coral health and resilience. Front Microbiol 8:341

Pochon X, Forsman ZH, Spalding HL, Padilla-Gamiño JL, Smith CM, Gates RD (2015) Depth specialization in mesophotic corals (Leptoseris spp.) and associated algal symbionts in Hawai'i. R Soc Open Sci 2:140351

Prada C, Mcllroy SE, Beltrán DM, Valint DJ, Ford SA, Hellberg ME, Coffroth MA (2014) Cryptic diversity hides host and habitat specialization in a gorgonian-algal symbiosis. Mol Ecol 23:3330-3340

Price MN, Dehal PS, Arkin AP (2010) FastTree 2-approximately maximum-likelihood trees for large alignments. PLOS ONE 5:e9490

R Core Team (2015) R: A language and environment for statistical computing R Foundation for Statistical Computing. R Foundation for Statistical Computing, Vienna, Austria

Ralph P, Gademann R (2005) Rapid Light Curves: a powerful tool to assess photosynthetic activity. Aquat Bot 82:222-237

Rideout JR, He Y, Navas-Molina JA, Walters WA, Ursell LK, Gibbons SM, Chase J, McDonald D, Gonzalez A, RobbinsPianka A, others (2014) Subsampled open-reference clustering creates consistent, comprehensive OTU definitions and scales to billions of sequences. Peerj 2:e545

Ring $\varnothing$ E, Hoseinifar SH, Ghosh K, Doan HV, Beck BR, Song SK (2018) Lactic acid bacteria in finfish-An update. Front microbiol 9:1818

Rohwer F, Seguritan V, Azam F, Knowlton N (2002) Diversity and distribution of coral-associated bacteria. Mar Ecol Prog Ser 243:1-10

Roitman S, López-Londoño T, Joseph Pollock F, Ritchie KB, Galindo-Martínez CT, Gómez-Campo K, GonzálezGuerrero LA, Pizarro V, López-Victoria M, Iglesias-Prieto R, Medina M (2020) Surviving marginalized reefs: assessing the implications of the microbiome on coral physiology and survivorship. Coral Reefs 39:795807

Rowan R, Knowlton N, Baker A, Jara J (1997) Landscape ecology of algal symbionts creates variation in episodes of coral bleaching. Nature 388:265-269

Scheufen T, Kramer WE, Iglesias-Prieto R, Enriquez S (2017) Seasonal variation modulates coral sensibility to heatstress and explains annual changes in coral productivity. Sci Rep 7:4937

Schloss PD, Westcott SL, Ryabin T, Hall JR, Hartmann M, Hollister EB, Lesniewski RA, Oakley BB, Parks DH, Robinson CJ, Sahl JW, Stres B, Thallinger GG, Van Horn DJ, Weber CF (2009) Introducing mothur: open-source, platform-independent, community-supported software for describing and comparing microbial communities. Appl Environ Microbiol 75:7537-7541

Stat M, Pochon X, Cowie ROM, Gates RD (2009) Specificity in communities of Symbiodinium in corals from Johnston Atoll. Mar Ecol Prog Ser 386:83-96

Stat M, Bird CE, Pochon X, Chasqui L, Chauka L, Concepcion GT, Logan D, Takabayashi M, Toonen RJ, Gates RD (2011) Variation in Symbiodinium ITS2 sequence assemblages among coral colonies. PLos ONE 6:e15854

Stoddart DR (1969) Ecology and morphology of recent coral reefs. Biol Rev 44:433-498

Thompson JR, Rivera HE, Closek CJ, Medina M (2015) Microbes in the coral holobiont: partners through evolution, development, and ecological interactions. Front Cell Infect Microbiol 4:1-20 
bioRxiv preprint doi: https://doi.org/10.1101/2021.10.18.464812; this version posted October 18, 2021. The copyright holder for this preprint (which was not certified by peer review) is the author/funder, who has granted bioRxiv a license to display the preprint in perpetuity. It is made available under aCC-BY 4.0 International license.

637

638

639

640

641

642

643

644

645

646

647

648
Van Veghel MLJ (1994) Polymorphism in the Caribbean reef building coral Montastrea annularis. Ph.D. thesis. University of Amsterdam, p128

Vermeij MJA, Bak RPM (2002) How are coral populations structured by light? Marine light regimes and the distribution of Madracis. Mar Ecol Prog Ser 233:105-116

Warner ME, LaJeunesse TC, Robison JD, Thur RM (2006) The ecological distribution and comparative photobiology of symbiotic dinoflagellates from reef corals in Belize: potential implications for coral bleaching. Limnol Oceanogr 51:1887-1897

Weil E, Knowlton N (1994) A multi-character analysis of the Caribbean coral Montastraea annularis (Ellis and Solander, 1786) and its two sibling species, M. faveolata (Ellis and Solander, 1786) and M. franksi (Gregory, 1895). Bull Mar Sci 55:151-175

Wickham H (2009) ggplot2: elegant graphics for data analysis. Springer, New York 